Trauma Surgery \& Acute Care Open

ORIGINAL ARTICLE

\title{
Trauma advanced practice provider programme development in an academic setting to optimize care coordination
}

\author{
Michelle C Woodfall, ${ }^{1}$ Timothy D Browder, ${ }^{2}$ Jesus M Alfaro, ${ }^{1}$ Meghan A Claudius, ${ }^{1}$ \\ Garrett K Chan, ${ }^{1}$ Denise Greci Robinson, ${ }^{1}$ David A Spain ${ }^{2}$
}

${ }^{1}$ Stanford Healthcare, Stanford, California, USA

${ }^{2}$ Department of Surgery, Stanford University, Stanford, California, USA

\section{Correspondence to Dr David A Spain;} dspain@stanford.edu

Presented at the 2015 Trauma Quality Improvement Program (TQIP) Annual Scientific Meeting, Nashville, TN, November $15-17$ $2015 \mathrm{e} 000068$

Received 21 November 2016 Revised 26 December 2016 Accepted 2 January 2017

\footnotetext{
To cite: Woodfall MC, Browder TD, Alfaro JM, et al. Trauma Surg Acute Care Open Published Online First: [please include Day Month Year] doi:10.1136/ tsaco-2016-000068
}

ABSTRACT

Background Benchmark data from the Trauma Quality Improvement Program (TQIP) identified an opportunity for improvement in our trauma programme. Our unexpected return to the intensive care unit (ICU) was found to be higher than the national averages and we also noticed that our readmission rate had increased. We chose to address these complications as continuous quality improvement projects. It was hypothesized that restructuring the workflow of the trauma advanced practice providers (APPs) to focus on the delivery of comprehensive clinical care would decrease return to ICU and readmission rates of trauma patients.

Methods The development of the APP programme occurred from 2012 to 2014 . First, APP daily shifts were extended to mirror the resident physicians' coverage. Second, the APPs' original job description was expanded from 'task-oriented' workflow to providing comprehensive clinical care. Third, the APPs were involved in the evaluation and decision-making process for transferring trauma patients from the ICU. Finally, the APPs implemented a new discharge process that included all information in a standardized format and a follow-up phone call 24-48 hours after discharge. The trauma registry at our verified, academic level I trauma center was use to assess our ICU and hospital readmission rates during the time we instituted the new APP workflow programme.

Results In 2012, our ICU readmission rate was 5.7\% ( $\mathrm{TQIP}=1.9 \%$ ) but then decreased to $4.4 \%$ in 2013 (TQIP $=2.5 \%)$ and $2.1 \%$ in $2014(\mathrm{TQIP}=2.8 \%)$. Our hospital readmission rate was $2.0 \%$ in 2012 but then decreased to $1.38 \%$ and $0.96 \%$ over the next 2 years.

Conclusions After extending the APP service coverage, implementing a comprehensive clinical care model and standardizing the discharge process, our unplanned return to ICU rates have decreased to below the TQIP national average and hospital readmission rates have also decreased by half.

Level of evidence III.

\section{INTRODUCTION}

One of the hallmarks of trauma care is a commitment to continually assessing our results and looking for opportunities to improve the care of our patients. In fact, the 'Performance Improvement and Patient Safety' chapter of the Resources for Optimal Care of the Injured Patient 2014 "calls for each trauma program to demonstrate a continuous process of monitoring, assessment, and management directed at improving care". ${ }^{1}$ However, some of the challenges have been identifying opportunities and having a comparison with which to measure your performance. To that end, the American College of Surgeons Committee on Trauma on Trauma (COT) developed the Trauma Quality Improvement Program (TQIP). ${ }^{2}$

As noted on their website, "TQIP accomplishes its work by collecting data from your trauma center, providing feedback about your center's performance, and identifying institutional characteristics that your trauma center staff can implement to improve patient outcomes. The program uses risk-adjusted benchmarking to provide your hospital with accurate national comparisons." ${ }^{2}$ In 2013, benchmark data from TQIP identified an opportunity for improvement in our trauma programme. Our unexpected return to the intensive care unit (ICU) was found to be higher than the national averages and we also noticed that our hospital readmission rate had increased. We chose to address these complications as continuous quality improvement projects. It was hypothesized that restructuring the workflow of the trauma advanced practice providers (APPs; trauma nurse practitioners and physician assistants) to focus on the delivery of comprehensive clinical care would decrease unplanned return to ICU and readmission rates of trauma patients.

\section{METHODS}

In 2013, we noted that our 2012 TQIP Benchmark Report had an unexpected return to the ICU that was much higher the national average. We also noted, from our institutional trauma registry, that our hospital readmission rate had increased over 3 consecutive years to $2 \%$. As a quality assurance initiative, we restructured the workflow of our trauma APPs (nurse practitioners and physician assistants) to focus on these issues in a project that we termed 'comprehensive clinical care'. The main components of this initiative were to have the APPs assume the majority of care for the trauma patients by: (1) standardizing the ICU transfer process, (2) having the APPs be primary care providers on the ward, (3) standardize the discharge process, (4) calling all patients within 24-48 hours of discharge and (5) organizing an APP lead trauma clinic for outpatient follow-up.

When trauma ICU patients were deemed stable for transfer to the floor, the trauma APPs provided 


\section{RN Trauma Patient Discharge Checklist:}

(RN Instructions: Please ensure each item below

has been completed and included within this discharge folder.)

$\square$ AVS or Interagency Discharge Summary and Orders

$\square$ Discharge Summary

Prescription for pain medication

Regular prescription faxed

Injury education material

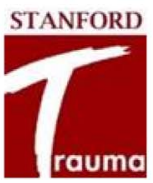

Figure 1 Registered nurse (RN) trauma patient discharge checklist. AVS, after visit summary. 
an independent assessment and wrote transfer orders to the ward if they agreed. The trauma surgeon on call adjudicated any differences of opinion. The trauma APPs then became the primary care providers for trauma patients on the ward, coordinating all aspect of their care. The trauma APPs also developed a standardized discharge process that included a checklist for the discharging nurse (figure 1), information on follow-up appointments, a pamphlet for the patient that included frequently used clinic phone numbers, and information on obtaining disability forms, medical records and radiological studies. The trauma APPs instituted a follow-up phone call programme that contacted trauma patients 24-36 hours after discharge to inquire about pain management, development of new symptoms and status of follow-up appointments. Finally, we also converted our case manager and social worker from unit-based model to a service-based model with dedicated trauma service personnel from Monday to Friday. In addition, the case manager's office was co-located with the trauma APPs to facilitate communication and collaboration.

We used our annual TQIP benchmark reports from 2012 to 2013 and 2014 to trend our unplanned return to ICU rate before (2012), during (2013) and after (2014) this restructuring. Since the elderly patient population was the largest contributing segment, we also reviewed the unplanned ICU readmission rate for this group as well. We also used our institutional trauma registry to track our unplanned hospital readmission rate during this same time frame (TQIP did not track hospital readmission at this time). Changes in our ICU readmission rate compared with the TQIP national average were analyzed using $\chi^{2}$ testing.

\section{RESULTS}

During the 3 years of this study, there were no significant differences in trauma volume, patient age, percent male, injury severity score, hospital and ICU length of stay (LOS) or mortality rate (table 1). In 2012, our ICU readmission rate was 5.7\% while the TQIP national average was $1.9 \%\left(\mathrm{p}<0.05\right.$ by $\left.\chi^{2}\right)$. After the initiation of the trauma APP programme, the ICU readmission rate decreased to $4.4 \%$ in 2013 (TQIP $=2.5 \%$ ) and to $2.1 \%$ in 2014 $\left(\mathrm{TQIP}=2.8 \%, \mathrm{p}=0.28\right.$ by $\left.\chi^{2}\right)$. ICU readmissions for geriatric patients similarly improved (from a high of $7.5 \%$ down to $4 \%$ ) but remained slightly above the TQIP national average for this population, although this difference was no longer statistically significant ( $\mathrm{p}=0.7$; figure 2). Our overall readmission rate to our hospital was $2.0 \%$ in 2012 but then decreased to $1.38 \%$ and $0.96 \%$ over the next 2 years (figure 3 ).

\section{DISCUSSION}

Using TQIP data and our own trauma registry, we were able to identify opportunities for improvement in the care of trauma

\begin{tabular}{|c|c|c|c|}
\hline & 2012 & 2013 & 2014 \\
\hline Trauma volume & 2459 & 2401 & 2609 \\
\hline Age (years) & 42.9 & 42.2 & 42.6 \\
\hline Males (\%) & 62.5 & 62.6 & 62.9 \\
\hline ISS & $7.1+8.1$ & $7.3+7.9$ & $7.3+7.4$ \\
\hline Hospital LOS (days) & $3.1+7.3$ & $2.9+11.6$ & $2.7+5.2$ \\
\hline ICU LOS (days) & $4.8+6.3$ & $4.4+4.9$ & $4.9+17.0$ \\
\hline Mortality (\%) & 2.1 & 2.0 & 2.4 \\
\hline
\end{tabular}

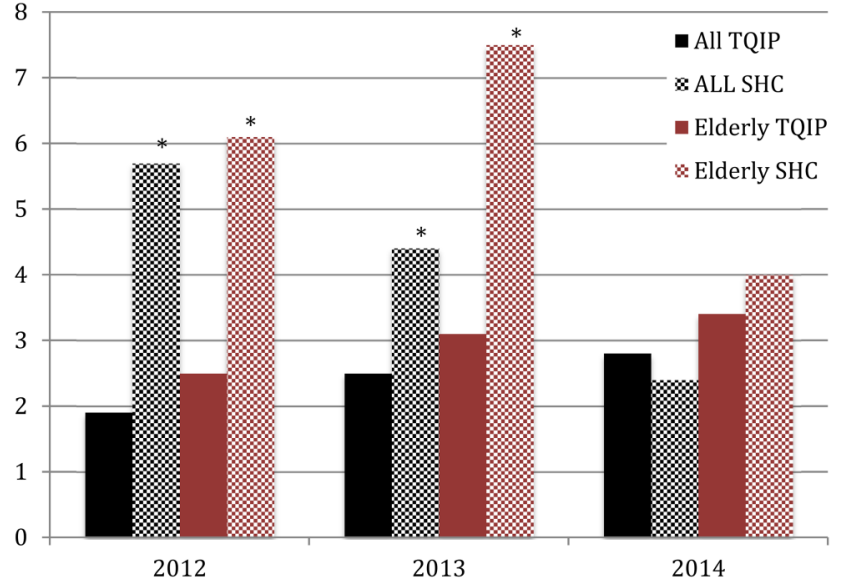

Figure 2 Unplanned return to the ICU rates. ${ }^{*} p<0.05$ by $\chi^{2}$. ICU, intensive care unit; SHC, Stanford Healthcare; TQIP, Trauma Quality Improvement Program.

patients. Specifically, we had seen an increase in the number of patients with unplanned readmissions to the ICU and to the hospitals. We interpreted these events as lack of coordination of care, especially around the time of handoffs (ICU-to-floor and inpatient-to-home). Through our Trauma Performance Improvement and Patient Safety (PIPS) committee, we initiated a quality improvement project. The main features of the programme were (1) restructuring the work flow to make ICU transfers and hospital discharge part of the workflow of our trauma APPs, (2) developing a discharge checklist and information packet for the patients and (3) a postdischarge phone call for early check-in with the patient. With these changes, we saw a significant decrease in our unplanned readmissions to the ICU as well as an improvement in our hospital readmission rates (figures 2 and 3).

Readmission to the ICU is a common event. In a systematic review of 31 studies, Wong et $a l^{3}$ found that $\sim 10 \%$ of all patients discharged from an ICU are readmitted during the same hospitalization. Not surprisingly severity of illness scores was higher among readmitted patients in most studies. However, readmission to the ICU was associated with mortality and longer LOS in the ICU and hospital, suggesting that any effort to decrease these events through coordination of care would be beneficial.

Collins et $a l^{4}$ demonstrated that the addition of an experienced acute care nurse practitioners to their trauma step-down unit results in an overall decrease LOS, as well increased both physician and nursing satisfaction. Similar to our model, the

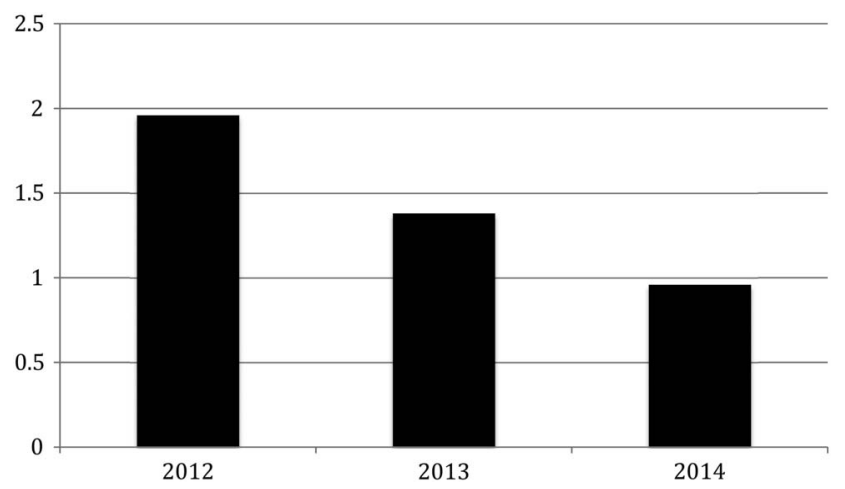

Figure 3 Unplanned hospital readmission rates. 
APP was 'the point of first contact for all patients, families, and nurses in the step-down area' and 'coordinated patient care with various members of the team including consulting services, ancillary services, and case management'. The APPs also provided detailed educational material to the family and patients, including discharge instructions. Similar to our study, they felt that the coordination, consistency and teamwork provide by the nurse practitioner were key elements in the success of the programme. $^{4}$

The hospital readmission of $1 \%$ is very low but is similar to other reports. ${ }^{5}$ This certainly underestimates the total readmission rate as we could only track readmissions to our hospital. Other single institutional studies have found readmission rates of $4-7 \% .{ }^{67}$ Copertino $\mathrm{et} \mathrm{al}^{7}$ found a $6.6 \%$ readmission rate at a median of 9 days after discharge in a single institution study. While many of these are likely to be unavoidable, major comorbidities were significant predictor, suggesting that coordination of discharge and early follow-up may help reduce readmission rates. Our low readmission rate (1-2\%) compared with the $4-7 \%$ reported in these studies may reflect different inclusion criteria in our trauma registries and databases.

More comprehensive readmission databases (using state or provincial wide data sources) have found somewhat higher unplanned readmission rates. Using a state wide data base from California, Olufajo $e t a l^{8}$ found a $7.6 \%$ readmission rate with $36 \%$ occurring at a different hospital. Moore et al ${ }^{9}$ found a similar 30-day readmission rate at $6 \%$, but this did increase to $21 \%$ when carried out to 6 months. Significantly, $77 \%$ of readmissions in their study were not to the index hospital, underscoring the need for thorough follow-up with trauma patients.

Haan $e a^{10}$ added trauma nurse practitioners to their team and used them to replace fellows on daily multidisciplinary discharge rounds. They found that 'nurse practitioners were able to perform at a level equal to that of senior house staff' and noted 'no decreases in the efficiency of the discharge round process'. Combined with these findings, non-rotating dedicated trauma APPs may provide better discharge outcomes for the polytrauma patient. Although anecdotal, we think this is especially helpful working as a team with the trauma case manager and social worker.

Incorporating APPs onto a trauma teams with trainees can present some challenges. Collins $e t \mathrm{al}^{4}$ found essentially a $100 \%$ agreement among trauma surgeons and nurses that the addition of trauma APPs was beneficial, although they did not survey residents or fellows. However, as Haan $e t a l^{10}$ noted, in this era of restricted duty hours and increasing volume, the APPs can help the team maintain efficiency. Kahn et $a l^{11}$ found that when APPs were introduced into a surgical ICU, almost half of their surgical residents reported a positive effect and only $31 \%$ felt it was detrimental.
The limitations of this study are that it was observational, the TQIP ICU readmission rates are not risk-adjusted and TQIP did not track hospital readmissions. Despite these limitations, these data support similar studies outlining the beneficial effects of incorporating APPs into the care of trauma patients. ${ }^{4} 1011$

\section{CONCLUSIONS}

By restructuring the workflow of our APPs to focus on the delivery of comprehensive care of trauma patients and standardizing the ICU transfer and hospital discharge processes, we were able to reduce unplanned readmissions to ICU and also decrease hospital readmission rates of trauma patients.

Acknowledgements The authors would like to thank Demetra Kokkinis, Stanford Trauma Registrar for her assistance with data collection and abstraction.

Competing interests None declared.

Provenance and peer review Not commissioned; externally peer reviewed.

Open Access This is an Open Access article distributed in accordance with the Creative Commons Attribution Non Commercial (CC BY-NC 4.0) license, which permits others to distribute, remix, adapt, build upon this work non-commercially, and license their derivative works on different terms, provided the original work is properly cited and the use is non-commercial. See: http://creativecommons.org/ licenses/by-nc/4.0/

\section{REFERENCES}

1 Rotondo MF, Cribari C, Smith RS. eds. Resources for optimal care of the injured patient 2014. Chicago, IL; American College of Surgeons, 2014:114-33.

2 https://www.facs.org/quality-programs/trauma/tqip

3 Wong EG, Parker AM, Leung DG, Brigham EP, Arbaje Al. Association of severity of illness and intensive care unit readmission: a systematic review. Heart Lung 2016;45:3-9

4 Collins N, Miller R, Kapu A, Martin R, Morton M, Forrester M, Atkinson S, Evans B, Wilkinson $\mathrm{L}$. Outcomes of adding acute care nurse practitioners to a level I trauma service with the goal of decreased length of stay and improved physician and nursing satisfaction. J Trauma Acute Care Surg 2014;76:353-7.

5 Ladha KS, Young JH, Ng DK, Efron DT, Haider AH. Factors affecting the likelihood of presentation to the emergency department of trauma patients after discharge. Ann Emerg Med 2011;58:431-7.

6 Morris DS, Rohrbach J, Sundaram LM, Sonnad S, Sarani B, Pascual J, Reilly P, Schwab CW, Simms C. Early hospital readmission in the trauma population: are the risk factors different? Injury 2014;45:56-60.

7 Copertino LM, McCormack JE, Rutigliano DN, Huang EC, Shapiro MJ, Vosswinkel JA, Jawa RS. Early unplanned hospital readmission after acute traumatic injury: the experience at a state-designated level-I trauma center. Am J Surg 2015;209:268-73.

8 Olufajo OA, Cooper Z, Yorkgitis BK, Najjar PA, Metcalfe D, Havens JM, Askari R, Brat GA, Haider $A H$, Salem A. The truth about trauma readmissions. Am J Surg 2016:211:649-55.

9 Moore L, Stelfox HT, Turgeon AF, Nathens AB, Le Sage N, Emond M, Bourgeois G, Lapointe J, Gagne M. Rates, patterns, and determinants of unplanned readmission after traumatic injury: a multicenter cohort study. Ann Surg 2014;259:374-80.

10 Haan JM, Dutton RP, Willis M, et al. Discharge rounds in the 80-hour workweek: importance of the trauma nurse practitioner. J Trauma 2007;63:339-43.

11 Kahn SA, Davis SA, Banes CT, Dennis BM, May AK, Gunter OD. Impact of advanced practice providers (nurse practitioners and physician assistants) on surgical residents' critical care experience. J Surg Res 2015;199:7-12. 